\title{
Clinical outcomes of minimally invasive endoscopic and conventional sternotomy approaches for atrial septal defect repair
}

\author{
Michael W.A. Chu, MD \\ Katie L. Losenno, MSc \\ Stephanie A. Fox, RRT \\ Corey Adams, MD \\ Hamad Al-Habib, MD \\ Ray Guo, MD \\ Alan H. Menkis, MD \\ Bob Kiaii, MD
}

From the Division of Cardiac Surgery, Department of Surgery, Western University, Lawson Health Research Institute, London, Ont.

\section{Correspondence to: \\ M. Chu \\ B6-106 University Campus, LHSC \\ 339 Windermere Rd. \\ London ON N6A 5A5 \\ Michael.Chu@Ihsc.on.ca}

DOI: $10.1503 /$ cjs. 012813
Background: Concerns remain that minimally invasive atrial septal defect (ASD) repair may compromise patient outcomes. We compared clinical outcomes of adult patients undergoing ASD repair via a minimally invasive endoscopic approach versus a "gold standard" sternotomy.

Methods: We retrospectively reviewed the clinical outcomes of consecutive patients who underwent ASD patch repair at our institution between 2002 and 2012. We compared inhospital/30-day mortality, postoperative complications, length of stay in hospital and in the intensive care unit and blood product requirements between patients who underwent right mini-thoracotomy (MT) and those who underwent conventional sternotomy.

Results: During the study period, 73 consecutive patients underwent ASD patch repair at our institution: 51 (age $47 \pm 16 \mathrm{yr}, 66.7 \%$ women) in the MT group and 22 (age $46 \pm 21 \mathrm{yr}, 59.1 \%$ women) in the sternotomy group. In-hospital mortality was similar between the 2 groups (MT 0\% v. sternotomy $4.5 \%, p=0.30$ ). There were no significant differences in any postoperative complications or blood product requirements. No patients in the MT group suffered stroke, retrograde aortic dissection or leg ischemia. Mean intensive care unit (MT $1.2 \pm 1.2 \mathrm{~d}$ v. sternotomy $1.7 \pm 2.2 \mathrm{~d}, p=0.26$ ) and hospital length of stays (MT $5.1 \pm 2.2 \mathrm{~d}$ v. sternotomy $6.3 \pm 3.6 \mathrm{~d}, p=0.17$ ) were similar between the groups; however, there was a trend toward fewer patients requiring prolonged hospital stays (> $10 \mathrm{~d})$ in the MT group (3.9\% v. $18.2 \%, p=0.06)$.

Conclusion: Repair of ostium secundum and sinus venosus ASD can be performed safely via MT endoscopic approach with similar outcomes as sternotomy. Patient preference for a more cosmetically appealing incision may be considered without concern of compromised outcomes.

Contexte : Des inquiétudes persistent au sujet des résultats potentiellement négatifs chez les patients soumis à une intervention de réparation de communication interauriculaire (CIA) minimalement effractive. Nous avons comparé les résultats cliniques chez des patients adultes soumis à une réparation de CIA par approche endoscopique minimalement effractive ou par sternotomie classique — 《l'étalon-or ».

Méthodes : Nous avons passé en revue de manière rétrospective les résultats cliniques chez des patients consécutifs qui ont subi un traitement d'occlusion de leur CIA dans notre établissement, entre 2002 et 2012. Nous avons comparé la mortalité en cours d'hospitalisation et à 30 jours, les complications postopératoires, la durée des séjours à l'hôpital et aux soins intensifs et le recours aux produits sanguins chez les patients selon qu'ils avaient subi une mini-thoracotomie (MT) ou une sternotomie classique.

Résultats : Durant la période de l'étude, 73 patients consécutifs ont subi un traitement d'occlusion de leur CIA dans notre établissement : 51 (âge $47 \pm 16$ ans, 66,7 \% femmes) dans le groupe MT et 22 (âge $46 \pm 21$ ans, 59,1 \% femmes) dans le groupe sternotomie. La mortalité perhospitalière a été similaire entre les 2 groupes (MT 0 \% c. sternotomie $4,5 \%, p=0,30)$. On n'a noté aucune différence significative quant aux complications postopératoires et aux besoins en produits sanguins. Aucun patient du groupe MT n'a subi d'AVC, de dissection aortique rétrograde ou d'ischémie à la jambe. La durée moyenne des séjours aux soins intensifs (MT 1,2 $\pm 1,2 \mathrm{j}$ c. sternotomie 1,7 $\pm 2,2 \mathrm{j}, p=0,26$ ) et à l'hôpital (MT 5,1 $\pm 2.2 \mathrm{j}$ c. sternotomie $6,3 \pm 3,6 \mathrm{j}, p=0,17$ ) a été similaire entre les groupes; toutefois, on a noté une tendance à un nombre moindre de patients nécessitant une hospitalisation prolongée (> $10 \mathrm{j}$ ) dans le groupe MT (3,9\% c. 18,2 \%,p=0,06).

Conclusion : La réparation de la CIA au niveau de l'ostium secundum et du sinus veineux peut se faire de manière sécuritaire par approche endoscopique MT, avec des résultats similaires à ceux de la sternotomie. On peut tenir compte de la préférence des patients pour une incision plus acceptable au plan esthétique sans crainte de compromettre les résultats. 
urgical repair of atrial septal defects (ASD) has been performed via midline sternotomy for decades with low perioperative risks and excellent long-term outcomes. ${ }^{1-3}$ Adult patients undergoing ASD closure are often younger, have few comorbidities and may have greater concerns about the cosmetic implications of open surgical repair. Percutaneous catheter-based ASD closure devices are being successfully used in patients with suitable anatomy, but require prosthetic device implantation and lifelong antiplatelet therapy. Minimally invasive surgical approaches include partial sternotomy, right mini-thoracotomy (MT), and totally endoscopic repair for closure of adult ASD. ${ }^{46}$ These techniques have been shown to have high rates of successful closure, low morbidity and decreased length of stay in hospital (LOS); ${ }^{6-9}$ however, concerns exist regarding improved cosmesis at the expense of increased cardiopulmonary bypass (CPB) duration and possible compromised patient outcomes..$^{10}$ In Canada, there is a widespread belief among patients and the medical community that minimally invasive techniques are not available, forcing patients to seek specialized care in the United States. ${ }^{11}$ However, there are a few centres that have substantial experience in minimally invasive approaches to ASD closure, mitral valve repair, tricuspid valve repair, ablation surgery and coronary artery bypass surgery. ${ }^{12}$

Many adult patients requiring ASD closure continue to seek less invasive, more cosmetically appealing options for surgical repair. We therefore sought to compare the outcomes of minimally invasive endoscopic and conventional sternotomy approaches for ASD repair.

\section{Methods}

\section{Patients}

We retrospectively reviewed the clinical outcomes of consecutive patients who underwent primary ASD patch repair at our institution between 2002 and 2012. The data were collected in our departmental database in accordance with the Society of Thoracic Surgeons definitions. We compared the outcomes of patients who underwent ASD repair by minimally invasive right minithoracotomy (MT) with the outcomes of those who underwent traditional sternotomy. The outcomes of interest included in-hospial and 30-day mortality; postoperative complications, including reoperation for bleeding, early reintervention, cardiac arrest or arrhythmia, neurological complications, respiratory failure, postoperative intra-aortic balloon pump, myocardial infarction, atrial fibrillation and wound infections; length of stay in hospital (LOS) and in the intensive care unit (ICU); and blood product requirements. The Western University Research Ethics Board approved the protocol for the investigation. The requirement for individual patient consent was waived in light of the retrospective nature of the database assessment.

\section{Minimally invasive endoscopic approach}

Patients in the MT group underwent double lumen endotracheal tube intubation with a transient single lung ventilation strategy. A 3-4 cm right anterolateral minithoracotomy incision and a $5 \mathrm{~mm}$ endoscope were used for surgical exposure (Fig. 1A and B and Fig. 2A and B). Venous cannulation consisted of a right percutaneous (16-Fr) superior vena cava (SVC) drainage catheter placed through the internal jugular vein, using ultrasonography and transesophageal echocardiography guidance for placement. The inferior vena cava (IVC) was cannulated with a multiport (21- or 25-Fr) venous drainage catheter via the right common femoral vein. The vena cava were isolated with separate tourniquet snares, similar to sternotomy-based surgery. Arterial cannulation consisted of a 17 - or 19-Fr arterial cannulae or $8 \mathrm{~mm}$ Dacron side graft via the right common femoral artery. Myocardial protection consisted of a transthoracic aortic cross-clamp and antegrade cardioplegia delivered into the ascending aorta. Secundum ASD were exposed through a midbody right atriotomy and closed with a patch of autologous pericardium or Dacron (Fig. 1C). Superior sinus venosus ASD with anomalous venous drainage underwent high right atriotomy incision to expose both the ASD and the origin of the anomalous vein. The left atrial baffle was constructed with autologous pericardium and the right atrial closure was augmented with a patch of autologous pericardium or Dacron. The right chest was flooded with $\mathrm{CO}_{2}$ throughout the procedure. Transesophageal echocardiography was used in all patients.

\section{Conventional sternotomy approach}

Patients in the sternotomy group underwent a standard midline sternotomy for surgical exposure with central arterial and venous cannulation (Fig. 2C). Conventional instruments were used, and the ASD repair was similar to that performed in the MT group. Transesophageal echocardiography was used in all patients.

\section{Statistical analysis}

All data were prospectively collected in a computerized database and imported into SPSS statistical software version 20.0 (SPSS Inc.) for analysis. All differences in continuous variables were tested for significance using the Student $t$ test and are presented as means \pm standard deviations unless otherwise noted. Differences in categorical variables were tested for significance with the $\chi^{2}$ or Fisher exact test, as appropriate, and are presented as proportions unless stated otherwise. Length of stay analysis was performed using the Mann-Whitney $U$ test. We considered results to be significant at $p<0.05$. 


\section{Results}

\section{Patients}

During the study period, 73 consecutive patients underwent primary ASD patch repair at our institution. Sixtyone patients $(83.6 \%)$ had an ostium secundum ASD and 12 patients $(16.4 \%)$ presented with sinus venosus defects with partial anomalous pulmonary venous connection (PAPVC). There were 51 patients (age $47.1 \pm 16.2 \mathrm{yr}$ ) in the MT group and 22 patients (age $45.9 \pm 20.5 \mathrm{yr}$ ) underwent traditional sternotomy. Patient characteristics in both groups were similar except for the higher proportion of patients in the sternotomy group with moderate to severe left ventricular dysfunction (MT 0\% v. sternotomy $18.2 \% ; p=0.007)$ and sinus venosus defects. More patients

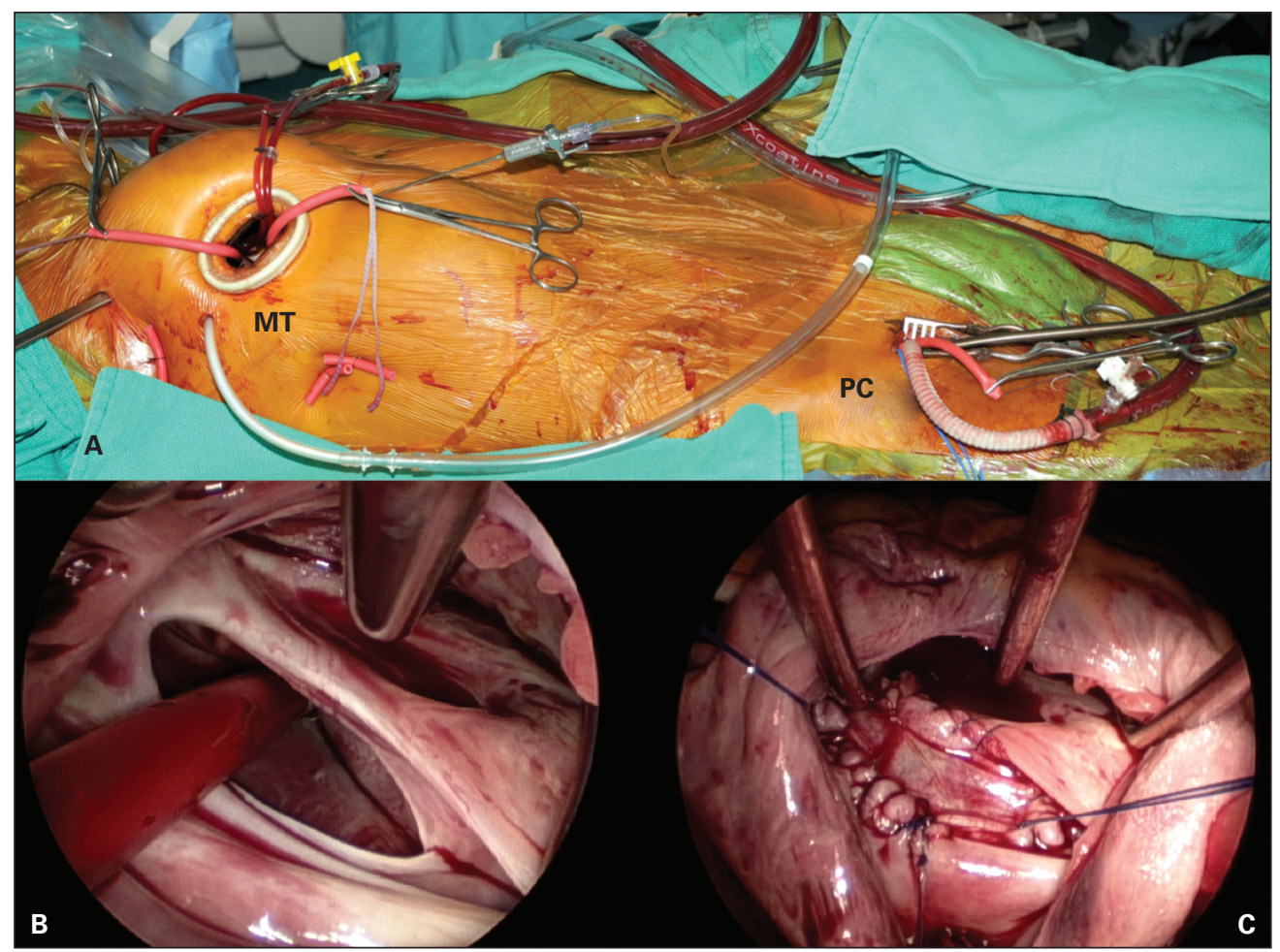

Fig. 1. (A) Intraoperative photograph demonstrating the $3-4 \mathrm{~cm}$ right minithoracotomy (MT) and peripheral cannulation (PC) set-up for minimally invasive, endoscopic atrial septal defect closure. (B) Endoscopic view of a large secundum atrial septal defect with a sump vent going through it. (C) Endoscopic view of the autologous pericardial patch closure of the secundum atrial septal defect.

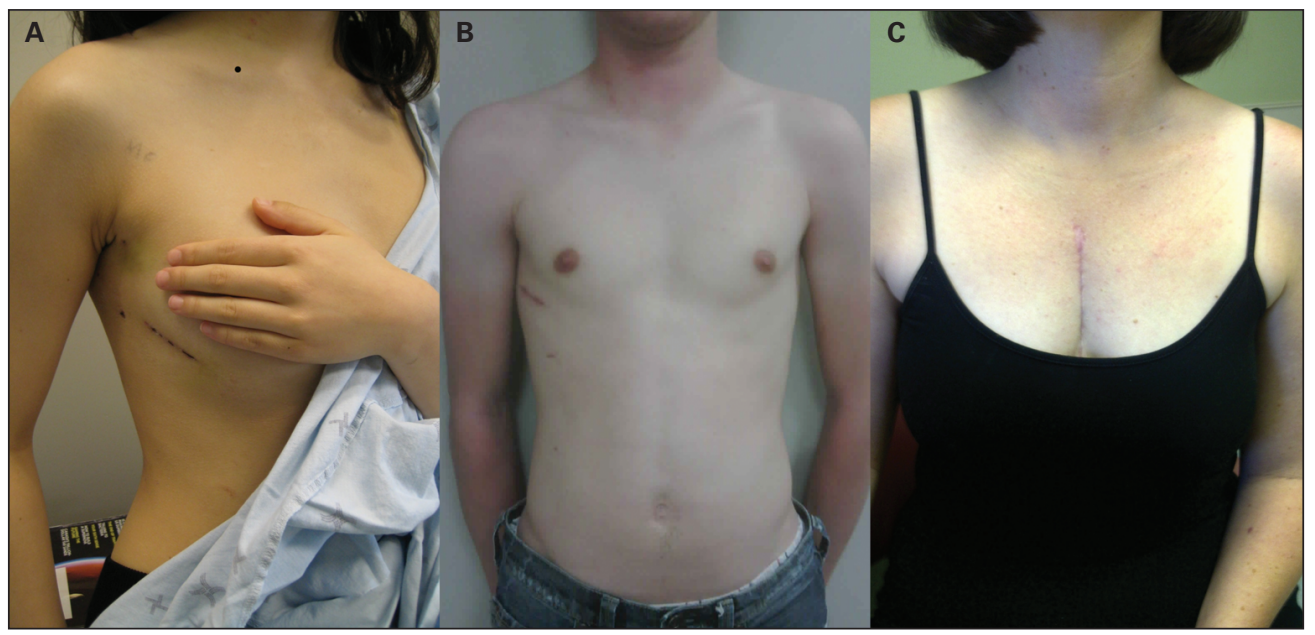

Fig. 2. Postoperative photographs demonstrating (A) the minithoracotomy wound in a female patient 5 days postoperatively and (B) in a male patient 4 weeks postoperatively, and (C) the sternotomy wound in female patient 2 months postoperatively. 
in the MT group had previously experienced either transient ischemic attack or stroke, and more patients in the sternotomy group had diabetes; however these differences were not significant. Complete patient characteristics are summarized in Table 1.

Surgical intervention was performed on an elective basis in $96.1 \%$ and $95.5 \%$ of the MT and sternotomy groups, respectively. Mean CPB duration was significantly longer in the MT group than the sternotomy group $(109.6 \pm 37.7$ $\min$ v. $81.8 \pm 43.6 \mathrm{~min}$, respectively, $p=0.007$ ); however, aortic cross-clamp duration was similar between the groups $(50.7 \pm 23.3 \mathrm{~min}$ v. $47.3 \pm 22.9 \mathrm{~min}$, respectively, $p=0.54)$. Complete operative details are shown in Table 2. There

\begin{tabular}{|c|c|c|c|}
\hline \multirow[b]{2}{*}{ Characteristic } & \multicolumn{2}{|c|}{ Group; no. $(\%)^{*}$} & \multirow[b]{2}{*}{$p$ value } \\
\hline & $\mathrm{MT}, n=51$ & Sternotomy, $n=22$ & \\
\hline Age, mean \pm SD yr & $47.1 \pm 16.2$ & $45.9 \pm 20.5$ & 0.80 \\
\hline Sex, male & $17(33.3)$ & $9(40.9)$ & 0.54 \\
\hline $\mathrm{BMI}$, mean $\pm \mathrm{SD}$ & $28.2 \pm 5.4$ & $29.1 \pm 8.0$ & 0.53 \\
\hline NYHA III/IV & $11(22.4)$ & $7(33.3)$ & 0.34 \\
\hline LV grade $3 / 4$ & 0 & $4(18.2)$ & 0.007 \\
\hline \multicolumn{4}{|l|}{ Comorbidities } \\
\hline Recent CHF & 0 & $1(4.5)$ & 0.30 \\
\hline CAD & $1(2.0)$ & $1(4.5)$ & 0.52 \\
\hline COPD & $1(2.0)$ & $1(4.5)$ & 0.52 \\
\hline $\begin{array}{l}\text { Cerebrovascular } \\
\text { disease }\end{array}$ & & & 0.28 \\
\hline TIA & $6(11.8)$ & $2(9.1)$ & \\
\hline Stroke & $9(17.6)$ & $1(4.5)$ & \\
\hline Diabetes & $3(5.9)$ & $4(18.2)$ & 0.19 \\
\hline PVD & $1(2.0)$ & $1(4.5)$ & 0.52 \\
\hline Renal failure & 0 & $1(4.5)$ & 0.30 \\
\hline \multicolumn{4}{|c|}{$\begin{array}{l}\mathrm{BMI}=\text { body mass index; } \mathrm{CAD}=\text { coronary artery disease; } \mathrm{CHF}=\text { congestive heart } \\
\text { failure; } \mathrm{COPD}=\text { chronic obstructive pulmonary disease; } \mathrm{LV}=\text { left ventricle; } \mathrm{MT}=\text { mini- } \\
\text { thoracotomy; NYHA = New York Heart Association; } \mathrm{PVD}=\text { peripheral vascular } \\
\text { disease; } \mathrm{SD}=\text { standard deviation; TIA = transient ischemic attack. } \\
{ }^{*} \text { Unless otherwise indicated. }\end{array}$} \\
\hline
\end{tabular}

were no in-hospital deaths in the MT group and 1 (4.5\%) in the sternotomy group $(p=0.30)$. The only patient who died in hospital/within the 30 days postsurgery was a 64year-old man with diabetes, coronary artery disease, renal failure and a sinus venosus ASD. This patient underwent conventional sternotomy with ASD and partial anomalous pulmonary vein repair. His postoperative course was complicated by ischemic bowel and subsequent death.

There were no significant differences in the incidence of any postoperative complications (Table 3), requirement for blood transfusions (Fig. 3) or LOS between the groups. When considering overall morbidity measured as a composite of any of 10 major complications, patients undergoing minimally invasive ASD closure experienced one-third of the complications experienced by patients in the sternotomy group, although this did not reach statistical significance. There was a trend toward significantly fewer patients requiring prolonged LOS $(>10 \mathrm{~d})$ in the MT than the sternotomy group (3.9\% v. $18.2 \%$; $p=0.06$; Table 3). No patients in either group experienced any neurologic complications or postoperative myocardial infarction. One patient in the MT group required conversion to sternotomy after successful endoscopic ASD closure due to inadvertent exsanguination from the indwelling percutaneous SVC cannulae after the chest was closed. This complication has been addressed by relocating the SVC cannulae within the surgical field and creating a comprehensive checklist for the entire team to review for peripheral cannulation (Fig. 4).

\section{Discussion}

Results of conventional surgical ASD patch closure are excellent with low operative mortality and morbidity. ${ }^{1-3}$ However, patients undergoing ASD repair are often younger and relatively healthier than the typical cardiac surgical population and are often interested in less invasive

\begin{tabular}{|c|c|c|c|}
\hline \multirow[b]{2}{*}{ Operative detail } & \multicolumn{2}{|c|}{ Group; no. $(\%)^{*}$} & \multirow[b]{2}{*}{$p$ value } \\
\hline & $\mathrm{MT}, n=51$ & Sternotomy, $n=22$ & \\
\hline Secundum ASD repair & $46(90.2)$ & $15(68.2)$ & \\
\hline Sinus venosus ASD \& PAPVC & $5(9.8)$ & $7(31.8)$ & 0.020 \\
\hline \multicolumn{4}{|l|}{ Concomitant procedures } \\
\hline Tricuspid valve repair & $7(13.7)$ & $4(18.2)$ & 0.72 \\
\hline Cryoablation & $3(5.9)$ & $2(9.1)$ & 0.63 \\
\hline Urgency & & & $>0.99$ \\
\hline Elective & $49(96.1)$ & $21(95.5)$ & \\
\hline Urgent & 2 (3.9) & $1(4.5)$ & \\
\hline \multicolumn{4}{|l|}{ Perfusion details } \\
\hline Cardiopulmonary bypass duration \pm SD min & $109.6 \pm 37.7$ & $81.8 \pm 43.6$ & 0.007 \\
\hline Cross-clamp duration \pm SD min & $50.7 \pm 23.3$ & $47.3 \pm 22.9$ & 0.54 \\
\hline
\end{tabular}


surgical approaches. Furthermore, given the increased prevalence of women with ASD, the importance of a more cosmetically appealing incision may be even greater. While several percutaneous closure devices have been used with good outcomes, ${ }^{13,14}$ these devices are indicated for relatively small secundum ASD closure and may not be applied in the setting of large ASD, those with an inadequate rim for device fixation or sinus venosus defects. Percutaneous ASD closure may also be associated with serious cardiac complications, such as device migration, neurologic events, obstruction to systemic and pulmonary venous drainage, endocarditis, postprocedural thromboemobolic risk, and less efficacious long-term results. ${ }^{13,15}$

Although minimally invasive endoscopic approaches have been previously applied with excellent outcomes, ${ }^{6,7,9}$ traditionalists remain concerned that the less invasive approach provides cosmesis at the expense of the excellent patient outcomes typical of conventional surgery. Our results suggest that minimally invasive endoscopic ASD closure and conventional ASD closure result in similar patient outcomes as closure via conventional sternotomy. As expected, both groups experienced relatively few major complications; therefore, demonstrating any superiority in the MT group is difficult. However, postoperative morbidity, as measured by a composite of any of 10 major complications, was lower in patients undergoing minimally invasive surgery. Several groups have previously reported reduced LOS in patients undergoing less invasive surgical techniques, ${ }^{8}$ which was also noted in the present investigation. Patients undergoing endoscopic ASD repair were discharged from hospital on average 1 day sooner than patients in the sternotomy group, although this difference did not reach statistical significance. There was a trend toward a decreased number of patients requiring prolonged LOS (>10 d) in the MT group, which likely reflects the decreased incidence of major complications in patients undergoing minimally invasive surgery. Patients in both groups rarely required blood transfusions; however, when needed, transfusion was most commonly related to intraoperative hemodilution.

Although minimally invasive ASD closure resulted in excellent outcomes, we experienced 1 major complication of the endoscopic technique. After successful endoscopic ASD closure, 1 patient required a conversion to a sternotomy as a result of inadvertent exsanguination from the percutaneous SVC cannulae as the CPB machine was detached at the end of the procedure. Her postoperative course was prolonged because she underwent hypothermia protocol in the intensive care unit to minimize the risk of a neurologic insult during the period of hypotension. She was successfully extubated with no neurologic insult, was eventually discharged home and was able to make a full recovery. While some groups have reported increased incidence of phrenic nerve injury with a minimally invasive approach, we did not experience this complication in this population.

There were more patients in the sternotomy group who had undergone repair of sinus venosus defects and PAPVC, because early in our experience, we had a preference for repairing these lesions via sternotomy. However, more recent experience has allowed us to repair more complex ASD anatomy via a minimally invasive approach without much added difficulty. There are 2 anatomic details that we consider before proceeding with a minimally invasive

\begin{tabular}{|c|c|c|c|}
\hline \multirow[b]{2}{*}{ Complication } & \multicolumn{2}{|c|}{ Group; no. $(\%)^{*}$} & \multirow[b]{2}{*}{$p$ value } \\
\hline & $\mathrm{MT}, n=51$ & Sternotomy, $n=22$ & \\
\hline Death & 0 & $1(4.5)$ & 0.30 \\
\hline Reoperation for bleeding & 0 & $1(4.5)$ & 0.30 \\
\hline Early reintervention & $2(3.9)$ & $1(4.5)$ & $>0.99$ \\
\hline Arrest or serious arrhythmia & $3(5.9)$ & $3(13.5)$ & 0.36 \\
\hline Neurological complication & 0 & 0 & \\
\hline Respiratory failure & $1(2.0)$ & $1(4.5)$ & 0.52 \\
\hline Postoperative IABP & 0 & $1(4.5)$ & 0.30 \\
\hline Myocardial infarction & 0 & 0 & \\
\hline Atrial fibrillation & $3(5.9)$ & $3(13.6)$ & 0.36 \\
\hline Wound infection & 0 & $1(4.5)$ & 0.30 \\
\hline Any of 10 major complications & $3(5.9)$ & $4(18.2)$ & 0.19 \\
\hline \multicolumn{4}{|l|}{ LOS } \\
\hline$I C U L O S \pm S D d$ & $1.2 \pm 1.2$ & $1.7 \pm 2.2$ & 0.26 \\
\hline ICU LOS $>4$ days & $1(2.0)$ & $2(9.1)$ & 0.21 \\
\hline Hospital LOS \pm SD d & $5.1 \pm 2.2$ & $6.3 \pm 3.6$ & 0.17 \\
\hline Hospital LOS > 10 days & 2 (3.9) & $4(18.2)$ & 0.06 \\
\hline
\end{tabular}


approach in patients with a sinus venosus defect with PAPVC. First, we measure the distance between the insertion of the anomalous veins into the SVC and the interatrial communication. If a preoperative computed tomography scan shows that the anomalous veins insert into the SVC within $2.5-3 \mathrm{~cm}$ of the interatrial communication, it can usually be repaired using a minimally invasive approach. Second, the SVC must be of reasonable calibre to allow for baffle reconstruction while maintaining SVC patency after the right atrial patch construction for a minimally invasive approach. If the SVC is very small and we anticipate performing a Warden procedure (SVC to right atrial appendage bypass), then we prefer to perform these cases through sternotomy. Using these guidelines for patient selection, we have found that the described operative technique allows for excellent exposure and baffle construction required to adequately treat sinus venosus defects with PAPVC.

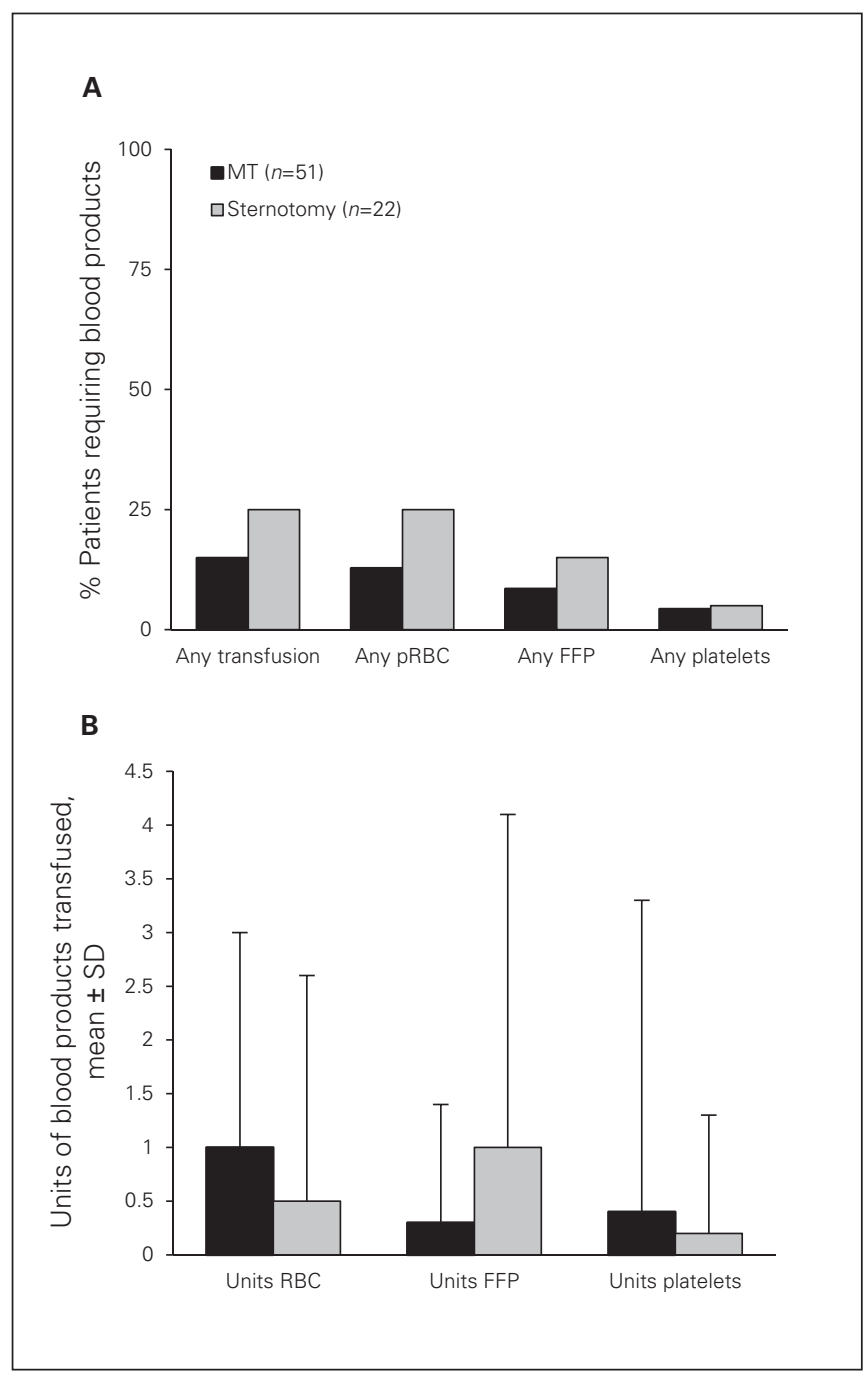

Fig. 3. Requirement for blood transfusions during hospital admission. FFP = fresh frozen plasma; $M T$ = minithoracotomy; $\mathrm{pRBC}=$ packed red blood cells; $\mathrm{SD}=$ standard deviation.

\section{Limitations}

Our investigation has several important limitations, namely the modest sample size and differences in the patient populations. While both groups were well matched for age and sex, there were differences in the left ventricular function and sinus venosus defects between the groups. This report is subject to all the usual limitations of an observational case series. Finally, although we present ASD closures performed during the same time period by various surgeons, a

\section{LHSC NECK LINE INSERTION CHECKLIST \\ INSIDE OPERATIVE FIELD Venous Neck Line}

Insertion Protocol

10,000 units. Heparin/1 L NS

$\square$ ACT control sample to perfusionists

$\square$ Patient prepped and draped in the normal fashion

$\square$ Both guidewires inserted under U/S guidance, TEE confirmation of neckline guidewire in RV

$\square$ Lines on table

$\square$ 5,000 units Heparin given (systemically) to patient by anesthesia

$\square$ Prior to insertion, venous neck cannula flushed with heparinized NS

$\square$ Venous neck cannula inserted by anesthesia

$\square \cup$ tube attached to cannula

$\square 3 / 8$ inch tubing attached to $U$ tube and back filled

$\square$ Tubing clamp placed at proximal end by surgeon - Distal to the stopcock

$\square$ Sterile IV set attached to venous cannula with continuous flush with heparinized NS (controlled by surgeon)

$\square$ Neck cannula secured (sutured and taped) to patient by surgeon

Tubing clamp placed at distal end of flushed 3/8 venous line

$\square$ Attached to $Y$ connector $(3 / 8 \times 3 / 8 \times 3 / 8$ for Resting Heart System, $1 / 2 \times 3 / 8 \times 3 / 8$ for conventional system) to common venous line - Proper orientation of " $Y$ " checked by perfusion

$\square$ Neck line attached to connector

$\square$ Patient systemically heparinized

$\square$ Common venous return line clamped (1) by perfusionists

$\square$ Heparin flush turned off by anesthesia - direct communication

$\square$ Femoral arterial cannula inserted

$\square$ Femoral venous line inserted

$\square$ Clamps removed from neck line - direct communication

$\square$ Neck Line drainage verified by perfusionist

Fig. 4. Percutaneous neck line checklist. $A C T=$ average clotting time; $N S=$ normal saline; $\mathrm{RV}=$ right ventricle; TEE = transesophageal echocardiography; U/S = ultrasonography. 
referral bias has favoured an MT approach for most cases, with a few still being performed via sternotomy by a smaller number of surgeons.

\section{Conclusion}

In experienced centres in Canada, repair of secundum and sinus venosus ASD with PAPVC can be performed safely via $\mathrm{MT}$ with similarly excellent outcomes as sternotomy. These less invasive techniques allow for a more cosmetically appealing incision without compromising patient outcomes.

Competing interests: M.W.A. Chu has received speaker honoraria from Medtronic Canada, and Edwards Life Sciences to teach minimally invasive surgical techniques. B. Kiaii has received honoraria from Medtronic for acting as a consultant and speaker. No other competing interests declared.

Contributors: M.W.A. Chu, K.L. Losenno, H. Al Habib and A.H. Menkis designed the study. M.W.A. Chu, K.L. Losenno and C. Adams acquired the data, which M.W.A. Chu, K.L. Losenno, R. Guo and B. Kiaii analyzed. M.W.A. Chu, K.L. Losenno and H. Al Habib wrote the article, which all authors reviewed and approved for publication.

\section{References}

1. Chang CH, Lin PJ, Chu JJ, et al. Surgical closure of atrial septal defect. Minimally invasive cardiac surgery or median sternotomy? Surg Endosc 1998;12:820-4.

2. Horvath KA, Burke RP, Collins JJ Jr, et al. Surgical treatment of adult atrial septal defect: early and long-term results. $7 \mathrm{Am}$ Coll Cardiol 1992;20:1156-9.

3. Murphy JG, Gersh BJ, McGoon MD, et al. Long-term outcome after surgical repair of isolated atrial septal defect: follow-up at 27-32 years. N Engl 7 Med 1990;323:1645-50.

4. Black MD, Freedom RM. Minimally invasive repair of atrial septal defects. Ann Thorac Surg 1998;65:765-7.
5. Cremer JT, Böning A, Anssar MB, et al. Different approaches for minimally invasive closure of atrial septal defects. Ann Thorac Surg 1999;67:1648-52.

6. Casselman FP, Dom H, De Bruyne B, et al. Thoracoscopic ASD closure is a reliable supplement for percutaneous treatment. Heart 2005; 91:791-4.

7. Ma ZS, Dong MF, Yin QY, et al. Totally thoracoscopic repair of atrial septal defect without robotic assistance: a single-center experience. 7 Thorac Cardiovasc Surg 2011;141:1380-3.

8. Ryan WH, Cheirif J, Dewey TM, et al. Safety and efficacy of minimally invasive atrial septal defect closure. Ann Thorac Surg 2003;75:1532-4.

9. Vistarini N, Aiello M, Mattiucci G, et al. Port-access minimally invasive surgery for atrial septal defects: a 10-year single-center experience in 166 patients. 7 Thorac Cardiovasc Surg 2010;139:139-45.

10. Helps BA, Ross-Russell RI, Dicks-Mireaux C, et al. Phrenic nerve damage via a right thoracotomy in older children with secundum ASD. Ann Thorac Surg 1993;56:328-30.

11. Boesveld S. "It's my health, it's my choice," Danny Williams says. Globe and Mail [Toronto] 2010 Feb 23. Available: www.theglobeandmail .com/news/politics/its-my-health-its-my-choice-danny-williams-says /article4311853/ (accessed 2013 May 11).

12. Chu MW, Jeanmart $\mathrm{H}$, Cook $\mathrm{R}$, et al. Minimally invasive mitral valve surgery: the Canadian experience. Can f Cardiol 2010;26(Suppl D):103D.

13. Chessa M, Carminati M, Butera G, et al. Early and late complications associated with transcatheter occlusion of secundum atrial septal defect. 7 Am Coll Cardiol 2002;39:1061-5.

14. de Lezo SJ, Medina A, Romero M, et al. Effectiveness of percutaneous device occlusion for atrial septal defect in adult patients with pulmonary hypertension. Am Heart 7 2002;144:877-80.

15. Post MC, Suttorp MJ, Jaarsma W, et al. Comparison of outcome and complications using different types of devices for percutaneous closure of a secundum atrial septal defect in adults: a single-center experience. Catheter Cardiovasc Interv 2006;67:438-43. 